\title{
How Pharmacy Students Evaluate the Credibility of Scientific Information: A Qualitative Study
}

\author{
Shafi Habibi ${ }^{1,2, *}$, Seyede Nasrin Fatemi ${ }^{3}$, Leila Doshmangir ${ }^{2,4}$ \\ ${ }^{1}$ Department of Librarianship and Medical Information, School of Management and Medical Informatics, Tabriz University of Medical \\ Sciences, Tabriz, IRAN. \\ ${ }^{2}$ Iranian Center of Excellence in Health Management, School of Management and Medical Informatics, Tabriz University of Medical \\ Sciences, Tabriz, IRAN. \\ ${ }^{3} \mathrm{MSc}$ student in Librarianship and Medical Information, School of Management and Medical Informatics, Tabriz University of Medical \\ Sciences, Tabriz, IRAN. \\ ${ }^{4}$ Health Services Management Department, School of Management and Medical Informatics, Tabriz University of Medical Sciences, \\ Tabriz, IRAN.
}

\begin{abstract}
Objective: This research is aimed at exploring the evaluation of information credibility and its related criteria from the viewpoints and experiences of PhD students in pharmacy in Tabriz University of Medical Sciences, Iran. Methods: The qualitative data were collected through semi-structured interviews. Using convenience sampling method, 13 PhD students in pharmacy were selected. Rigor of the study was approved by member checking and external audit. A content analysis approach (inductive and deductive) was used for the analysis of the data. Results: Three themes, including "database evaluation", "information source evaluation" and "content evaluation", were extracted as the three most important components of the evaluation from students' viewpoint. Nine primary criteria were extracted for the evaluation of information, including accessibility, coverage, learnability, relevancy, accuracy authority, currency, replicability and source validity. The desired criteria were categorized after considering subject and concept proximity. Conclusion: This study revealed the criteria considered by students for evaluating information. Challenges and limitations regarding the evaluation of information were identified. The findings of the study will help the central library and librarians realize and address the challenges and limitations of information use.
\end{abstract}

Key words: Information Credibility, Evaluation Criteria, Source Selection Criteria, Use of Information, Pharmacy Students.

\section{INTRODUCTION}

Studies on the use of electronic resources by students - in particular, databases - indicate that students have access to a large number of resources for their research work, enabling them to search and use these resources. ${ }^{1-3}$ Researchers have used search operators and other facilities to create search statements and gain access to relevant information..$^{3-4}$ Together with search skills, researchers must critically evaluate information and competently use credible information in their studies. ${ }^{5}$ Scholars have evaluated credibility of information in different ways ${ }^{6}$ and have a different understanding of this concept that depends on the quality of users' human perception, which is obtained from a simultaneous evaluation of various dimensions of information and types of information needs. ${ }^{7}$ There are different criteria for assessing news information and in particular the required health information. ${ }^{8}$ Flanagin showed that users with different levels of motivation and ability consider different criteria when evaluating electronic information. ${ }^{6}$

Concerns regarding the credibility of information have increased since 1993, when for the first time, the Web became freely available to the public. ${ }^{9}$ Given the recent
Submission Date: 22-04-2018; Revision Date: 16-07-2018; Accepted Date: 23-10-2018

DOI: 10.5530/ijper.53.1.11 Correspondence: Shafi Habibi,

Department of Librarianship and Medical Information,

School of Management and Medical Informatics, Tabriz University of Medical Sciences, Daneshgah street, Tabriz, IRAN.

Postal Code: 5166614711. Phone: +98 9144116753 E-mail: sh-habibi@razi.tums. ac.ir

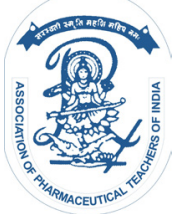

www.ijper.org 
advances in the Web, the scientific community has an increasing tendency to use the Web to retrieve information in various fields, including education and research. Although databases index journals by evaluating quality of articles, other tools that provide access to a large amount of information sources - such as Google Scholar - collect and index information from various resources, including information repositories and various journal sites without any evaluation or selection process. ${ }^{10}$ In addition to the need to distinguish between incredible and credible information, researchers must be able to select more reliable and higher-quality information to enhance the quality of their own studies. Therefore, it has become increasing apparent that to effectively use information published online, it is important to examine the ability of users to evaluate and identify credible information. Users must be familiar with the process of evaluating information credibility before deciding whether to use information sources. Compared to other groups, students have higher rate of information use and must be able to evaluate the credibility of information. The aim of this study was to investigate the experiences of pharmacy $\mathrm{PhD}$ students at Tabriz University of Medical Sciences (TUOMS) in evaluating credibility of information. This study was designed to fill the gap in the literature regarding the scientific and research-based understanding of the criteria used by students to evaluate the credibility of information used for research purposes. The results of this study can be used for modifying medical information systems curriculum (This course is presented to postgraduate students in one theoretical and practical unit. Students must take this course in their first semester to familiarize themselves with databases and acquire search skills). To improve students' information literacy and thus enhance the quality of the relevant studies.

\section{METHODS}

This is a qualitative study conducted using semi-structured interviews. In this study population was $\mathrm{PhD}$ students of the faculty of pharmacy. The Faculty of Pharmacy has seven academic departments, including pharmacology, pharmacognosy, medicinal chemistry, pharmaceutics, pharmaceutical biotechnology, clinical pharmacy and pharmaceutical and food control. The importance of using credible information in the field of pharmacy lies in the fact that this field is a major field of health. In addition, the high volume of scientific production of the Faculty of Pharmacy of Tabriz University of Medical Sciences compared with other medical sciences (according to the Ministry of Health
Scientometrics System) and the impact of using credible information on the reputation of the scientific productions of this faculty provided further motivation to select the $\mathrm{PhD}$ students of this college for interview.

Before starting the study, in consultation with several pharmacology professors, we identified the disciplines in which the use of credible information is highly important compared to other disciplines; as a result, studying the fields of pharmacology, pharmaceutics and medicinal chemistry were considered to be inclusion criteria. Selected students were interested in participating in the study, were studying one of the three abovementioned disciplines and were conducting a research project as part of writing a doctoral dissertation. Given that the junior (first-year) students have low level of knowledge and experience on the methods of searching and evaluating research data, these students were excluded from the study. The participants were selected using purposive sampling (one of the main types of non-probability sampling methods) according to the research objectives. For selecting students, the interviewer, an MSc student in medical librarianship and information science (S.F), created a friendly relationship with the study population and the students who were close to hand, were selected. A total of $13 \mathrm{PhD}$ students participated in the present study (six females and seven males), consisting of five medicinal chemistry students, four pharmaceutics students and four pharmacology students. Nine participants were fourth-year students, three were third-year students and one was a second-year student. The interview period was from December 2016 to February 2017 and was conducted at times convenient for the participants. Data were collected through interviews using of semi-structured questions. The interview guide was developed through literature review and the research team opinions. Number and order of questions verified through testing on non-study participants (Appendix A). To resolve any ambiguity and to effectively use experts' viewpoints, if necessary, we asked additional questions to generate further discussions and promote the comprehensive exploration of the subject matter. The interviews lasted between 45 and $60 \mathrm{~min}$. The participants were assured that the information would be kept confidential and that the recorded sounds would be deleted at the end of the investigation. Selecting interviewees continued to reach the point of no new data and no new themes.

Trustworthiness of the data was examined using the four criteria of Lincoln and Guba including conformability, credibility, dependability and fittingness or transferability. ${ }^{11}$ Credibility of the findings was done through appropriate interaction with the research participants and prolonged involvement of the researcher in the 
research. Conformability was examined by an external checker familiar with qualitative study. For this purpose, the extracted codes and categories were presented to the research participants and their appropriateness was controlled, verified and consensus was achieved in this regard. Member checking was used to confirm whether the researchers' interpretation of the interview data was congruent with what the participants intended to express the researcher. For dependability, the researcher accurately recorded and reported the research process such as code and recode procedure to allow for follow-up research by others.

A content analysis method was used for the data analysis with MAXQDA software. This qualitative method is suitable for summarizing the content of spoken and written information obtained from participants and for a deep description of the surveyed phenomenon, which cannot be obtained using quantitative methods. ${ }^{12}$ After each interview, the participants were handed the interview transcript to read and add their comments. Interviewees' responses related to the ratification of content, the authenticity of that which was said during the interview, corrections of language, clarifying unclear portions were obtained. Insights gained from data analysis of feedback comments on transcripts were sent to the interviewees and last feedback was recorded. This step helped the researcher to modify the other questions for future interviews and thereby improve the study. Directed content analysis was used for analyzing data. Analysis started with a relevant research finding as guidance for initial codes. After coding the texts of the interviews, the codes that were similar in meaning were placed in the same category. By clustering together similar categories, the main themes of the study were extracted and the relationships among the categories were determined.

\section{RESULTS}

Through the analysis of the data obtained from the interviews, we extracted the criteria considered by the participants and classified them into three themes: "database evaluation", "information source evaluation" and "content evaluation". Each theme included main and secondary criteria and each criterion described a special aspect considered by the participants in evaluating information. Each of the extracted themes and subthemes were supported by the selected interview texts.

\section{Database Evaluation}

Some of the criteria mentioned by the participants for evaluating information refer to the evaluation of databases to find the desired information. In other words, during the first stage of finding relevant information, the participants paid attention to the database that they were using. The criteria considered by the participants for evaluating databases include accessibility, coverage and learnability. In selecting a database, the students consider the abovementioned criteria and tend to make more use of databases with these features (Table 1).

\section{a) Accessibility}

Access to a database with no time limitation and without dependency on a location has a significant impact on the use of a database. This access is also important from the perspective of the participants who, in addition to complementing the Scopus database as a good database for searching required information, also mentioned restrictions in the use of this database. One of the participants said in this regard:

"Databases like Scopus are non-free databases that the university provides students access to after subscribing to them; but if you want to have access to Scopus from your house and download an article or read it online, you cannot; this is possible only from your university campus" (Interviewee no. 11)

Table 1: Database evaluation's themes, subthemes and issues extracted from the qualitative content

\begin{tabular}{|c|c|c|c|}
\hline Theme & Subtheme & Issue & Items \\
\hline \multirow{11}{*}{ 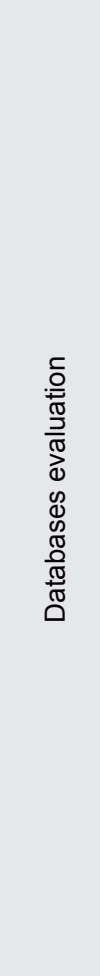 } & \multirow{3}{*}{ 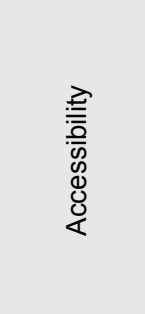 } & Easy access & $\begin{array}{l}\text { Access to } \\
\text { databases } \\
\text { anywhere }\end{array}$ \\
\hline & & \multirow[b]{2}{*}{ Free access } & $\begin{array}{l}\text { Using free } \\
\text { databases }\end{array}$ \\
\hline & & & $\begin{array}{c}\text { Using databases } \\
\text { subscribed by the } \\
\text { University }\end{array}$ \\
\hline & \multirow{2}{*}{ 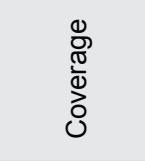 } & \multirow{2}{*}{ Indexed journal } & $\begin{array}{l}\text { Access to a large } \\
\text { number of journals }\end{array}$ \\
\hline & & & $\begin{array}{l}\text { Access to WOS } \\
\text { indexed journals }\end{array}$ \\
\hline & \multirow{6}{*}{ 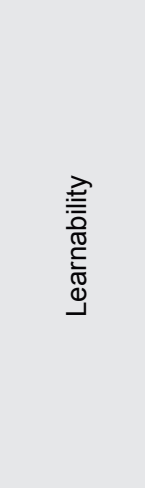 } & \multirow{3}{*}{ Convenient use } & $\begin{array}{c}\text { User-friendly } \\
\text { nature of } \\
\text { database's } \\
\text { interface }\end{array}$ \\
\hline & & & $\begin{array}{c}\text { Selectable search } \\
\text { options }\end{array}$ \\
\hline & & & Similar article view \\
\hline & & \multirow{3}{*}{ Previous familiarity } & $\begin{array}{l}\text { Trained by } \\
\text { professors }\end{array}$ \\
\hline & & & Trained by friends \\
\hline & & & $\begin{array}{l}\text { Trained by } \\
\text { workshops }\end{array}$ \\
\hline
\end{tabular}




\section{b) Database Coverage}

Coverage includes various aspects of access to information sources. It can refer to access to a large number and volume of information sources and required information, as well as to the amount of coverage in a particular field of interest. By providing access to more journals and consequently allowing for the possibility of retrieving more articles, a high number of journals indexed in a database, increases users' confidence in the obtained results. One of the participants notes on the coverage of databases:

“... I mostly use Science Direct. Most Science Direct journals in general are indexed in Web of Sciences (WOS). WOS also covers more journals ..." (Interviewee no. 9)

\section{c) Learnability}

Learnability is determined by the amount of effort required by the user to learn how to use a database. The ability to learn or become familiar with a database depends on two main factors: "convenient use of the database" and "previous familiarity with the database"." User-friendliness is a feature that increases the user's willingness to use the database. This factor can affect the use of a database that the user merely uses due to being familiar with the environment of the database. One of the participants mentioned this issue:

"In fact, it is easy to use and you can find your desired information there." (Interviewee no. 8)

Through provision of facilities to retrieve articles and use them efficiently, databases help users to apply different ways to more easily search for required information. The facilities provided by a database for a more convenient and useful search y include such search options as topic search, author search and related article views. Additionally, a former familiarity with databases through professors, friends or through taking part in workshops improves users' sense of trust and confidence in the database. In other words, databases that are introduced by professors, friends and through workshops were perceived to be more valid by the participants, who consequently had more confidence in search results and articles retrieved from these databases.

\section{Evaluating Information Resources}

The criteria that the students consider in evaluating the information provided by databases include two general subthemes: authority and source validity (Table 2).

\section{Authority}

The expertise and experience of the author and publisher is one of the most important criteria that students identify

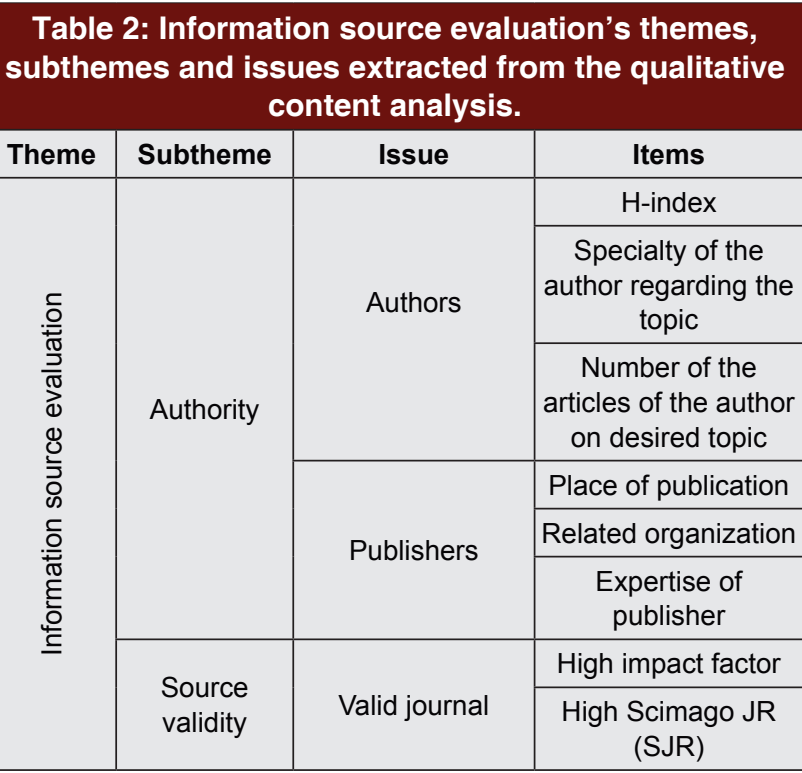

for evaluating credibility of information. Almost all of the participants mentioned this criterion, which reflects its importance. To evaluate the authority of an author, the participants evaluated such items as the author's h-index, specialty with respect to authors writing on the same topic and the number of articles published by the author on the desired topic. The participants believed that if a given scientific work is cited frequently in various articles, it means that this scientific work is credible. In this way, an author becomes familiar with other works and accordingly will be known as an authority with sufficient expertise and experience in the subject. Therefore, any scientific work published under the name of that author will be credible for users. Several participants pointed to the importance of this issue as follows:

"My supervisor emphasized that the first author or an author who has published a work should have worked in that field for some years and should have published subsequent articles in that field. He did not accept authors who had published only one article in that field and said that if their work was credible and they were expert in their field, they would write again and again in that field" (Interviewee no. 7)

From the participants' point of view, the place of publication (country) and the organization supporting the scientific work were also important in evaluating credibility of information. Lack of trust in a particular place or country among the participants in this study was one of the remarkable considerations mentioned by them. Although the participants acknowledged that this criterion was misguided, this distrust was nevertheless formed by observing a large number of poor scientific works published by authors from particular countries. 
Table 3: Content evaluation's themes, subthemes and issues extracted from the qualitative content analysis.

\begin{tabular}{|c|c|c|c|}
\hline Theme & Subtheme & Issue & Items \\
\hline \multirow{16}{*}{ 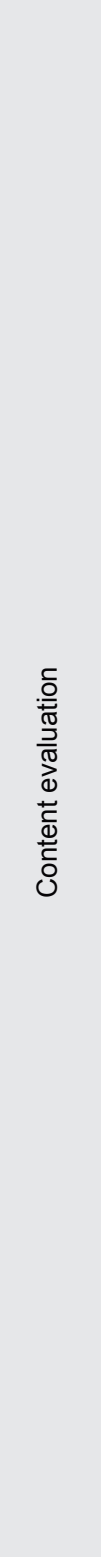 } & \multirow{6}{*}{ Accuracy } & \multirow{2}{*}{$\begin{array}{l}\text { Contents of a } \\
\text { paper }\end{array}$} & $\begin{array}{c}\text { Comparing } \\
\text { contents with other } \\
\text { papers }\end{array}$ \\
\hline & & & $\begin{array}{c}\text { Comparing } \\
\text { contents of } \\
\text { paper with prior } \\
\text { knowledge }\end{array}$ \\
\hline & & $\begin{array}{c}\text { Scrutiny of a } \\
\text { paper references } \\
\text { list }\end{array}$ & $\begin{array}{l}\text { Having credible } \\
\text { references }\end{array}$ \\
\hline & & \multirow{3}{*}{$\begin{array}{l}\text { Writing and } \\
\text { grammar }\end{array}$} & $\begin{array}{c}\text { Punctuation and } \\
\text { grammar }\end{array}$ \\
\hline & & & Reference style \\
\hline & & & Text coherence \\
\hline & \multirow{3}{*}{ Relevancy } & \multirow{3}{*}{ Relevant contents } & $\begin{array}{l}\text { Key words in the } \\
\text { title and abstract }\end{array}$ \\
\hline & & & $\begin{array}{l}\text { Key words in the } \\
\text { key word field }\end{array}$ \\
\hline & & & $\begin{array}{l}\text { Usefulness of } \\
\text { content for users }\end{array}$ \\
\hline & \multirow{5}{*}{ Replicability } & \multirow[b]{2}{*}{ Detailed methods } & Accurate methods \\
\hline & & & $\begin{array}{c}\text { Completeness of } \\
\text { details }\end{array}$ \\
\hline & & \multirow{2}{*}{$\begin{array}{l}\text { Materials and } \\
\text { equipment }\end{array}$} & $\begin{array}{c}\text { Availability } \\
\text { of necessary } \\
\text { materials and } \\
\text { equipment }\end{array}$ \\
\hline & & & $\begin{array}{l}\text { Possibility to } \\
\text { prepare according } \\
\text { to allocated budget }\end{array}$ \\
\hline & & Person's skill & $\begin{array}{l}\text { Knowledge and } \\
\text { skills of the person } \\
\text { to do the research } \\
\text { based on methods } \\
\text { of a paper }\end{array}$ \\
\hline & \multirow{2}{*}{ Currency } & \multirow{2}{*}{$\begin{array}{l}\text { Use of new } \\
\text { information }\end{array}$} & $\begin{array}{c}\text { Include up-to-date } \\
\text { information }\end{array}$ \\
\hline & & & $\begin{array}{l}\text { No duplicate } \\
\text { information }\end{array}$ \\
\hline
\end{tabular}

For this reason, several of the participants believed that it is useless to spend time studying papers written by authors from certain countries.

"It is important to know who the author is and for which country or institution the author or authors work for..." (Interviewee no. 5)

\section{Source Validity}

The high impact factor and SJR rank score are a strong indication of the credibility of the journal for students. Therefore, articles published in high-impact journals or high SJR scores will have more credibility from students' point of view.

\section{Content Evaluation}

After reviewing the abovementioned criteria which are included in previous classes, the students evaluated the contents provided in a scientific source in terms of accuracy, currency, replicability and relevancy (Table 3).

\section{Accuracy}

Accuracy means that the information provided by a scientific source is error-free, which was a quality emphasized by interviewees. The accuracy of information that is supposed to be used in a research work will directly affect the outcome of a scientific research. Accuracy is particularly important in the field of pharmacy. Given the limited time that students spend on research and the high laboratory costs of research, students have a higher sensitivity to information selection. As a result, students try to ensure the integrity and accuracy of the information that is supposed to provide a framework for their research such that the time and budget they spend on their study lead to a correct and desirable outcome. The participants in the study divided the criterion of accuracy into three issues: contents, references and writing. The participants referred to accuracy of the contents of scientific articles in various ways, such as "not limiting oneself to a single article and comparing the results of different articles, as well as comparing the information provided in scientific sources with their own knowledge and experience". At the same time, assessing the accuracy of information based on a student's previous knowledge is directly related to the student's knowledge of and experience in the related topic and is a skill that students acquire over time. One of the participants noted in this regard:

“....I don't do my study with only one article anymore; for example, right now I'm doing a study. I compare all the existing articles and decide what I should do..." (Interviewee no. 5)

The participants further referred to investigating the accuracy of references used in a scientific work. According to these participants, the references used by an author give some credibility for the provided information or in other words, validates the scientific power of the work. In fact, investigating the references of a paper is a way to evaluate the accuracy of its information.

“... for example, when I search an article, I should see whether the author has mentioned credible references to its contents" (Interviewee no. 1)

Another criterion that affects accuracy of information is whether the author pays attention to grammatical and writing rules in a scientific work. One of the participants noted in this regard: 
"There are original articles that ... lack coherence and are not reasonable. We put aside such articles and say that the author has botched the article... The author has written a scientific text with so many spelling mistakes and its references lack details" (Interviewee no. 12)

\section{Relevancy}

Relevancy is one of the most commonly used criteria that users apply to evaluate information. Most participants in the study referred to the relevance of the content: "Usually, I first inspect the title of the article, although the title is not more than one line. I also try to avoid prejudice. If the title attracts my attention and it seems interesting to me, I immediately read the abstract and if the abstract convinces me that it is a good article, I read the full-text article; otherwise I skip to the next article" (Interviewee no. 12)

\section{Currency}

To be up-to-date is another criterion that our participants noted. Researchers always seek to use new and up-todate information to ensure the novelty and usefulness of the materials provided in new published scientific works.

\section{Replicability}

Most of the participants referred to replicability as an important criterion. Replicability means, first, that it should be possible to repeat the study and, second, that the same results should be obtained in the repeated study. From students' point of view, different factors are involved in the potential replicability of a research study. Therefore, accurately investigating the methodology of a scientific work and evaluating it in terms of the correctness of the implemented procedure and the completeness of its details reveal to some extent its replicability.

The participants reported that the credibility and accuracy of information can be verified with details provided in the methods section. In other words, a study that shows the conditions of the experiment in detail is both more reliable and more applicable from students' point of view. Additionally, the implementation of the methods should be appropriate for the available facilities; in this case, the participants evaluated the replicability of the proposed implementation by testing it with a small sample size in the laboratory or in consultation with their professors. Some students noted the following:

"The other point is that what they have done is consistent with our facilities; for example, some articles are very good, but the university's facilities are not sufficient to repeat them. The other point is that we consult with our professors or conduct them as a pilot study to see if they are applicable so that we can choose the one that is easier." (Interviewee no. 3)

\section{DISCUSSION}

\section{Database Evaluation}

The results of the study showed that users tend to use information sources that require minimal effort to access. Therefore, information sources that are more available are more likely to be used. ${ }^{13}$ The high rate of use of free information sources is due to the poor quality of some of these sources ${ }^{14}$ and can affect the quality of students' studies. Accordingly, accessibility is one of the factors limiting the availability of information; this phenomenon might lower the study quality and diminish the credibility of papers extracted from students' studies. Another criterion related to the capabilities of databases was the database's coverage, namely, access to a database with more journals indexed, which allows easy access to a large volume of relevant information, thereby increasing trust in the retrieved results. Other studies have also found such an approach to using databases. ${ }^{6,15}$ User's satisfaction with the number of results retrieved in a database and his awareness of the fact that the database thoroughly covers the related topic assures him that there is no need to spend more time searching in different databases. This helps database creators to increase the number of users using their database and the confidence of these users in the results retrieved by expanding the coverage of the database. On the other hand, databases such as Google Scholar are becoming a more comprehensive search tool ${ }^{16}$ and will soon be able to resolve the issue of accessibility to bibliographic information. However, at present, the university can provide easy access to information resources by developing a search tool for integrated searches in subscribed databases.

Learnability of a database affects the desire of users to use it. ${ }^{17}$ User-friendliness, as a sub-criterion of learnability, is the most important reason for students' desire to use an information source. ${ }^{18}$ By reducing the anxiety caused by being unfamiliar with the database environment and by increasing the user's confidence during the search, this feature, increases the user's reuse intention. User's experience in using a given information source affects his perceived credibility of the information. ${ }^{6,19-20}$ It seems that the sub-criterion of learnability, encompassing the user-friendly properties and the degree of convenient use of a database, leads to a greater use of that database, which will ultimately result in its being credible. It seems that training users to use various databases and features is necessary to avoid the result that users limit themselves to a specific database. 


\section{Source Evaluation}

The credibility of the information provided by a scientific source and the corresponding level of users' trust in that information are greatly influenced by the author and publisher's experience and expertise because users believe that it is easier to trust information provided by specialists and reputed individuals who have gained credibility in publishing accurate information. ${ }^{15,21}$ Given the importance of this issue, the participants in the study mentioned such authority factors as author's h-index, author's expertise in that topic and number of articles the author has published on related topic and reported these factors as factors determining author credibility. Additionally, many studies that have provided a framework for evaluating the credibility of web-based information sources have mentioned authority as a key factor in evaluating the credibility of web-based information. ${ }^{14,22}$ It seems that this criterion allows students to take important steps to assess credible information.

\section{Content Evaluation}

Students compare information of articles with their former knowledge and other information sources to confirm or refute the accuracy of the information. ${ }^{23}$ Because judging the accuracy of information retrieved from a single source is risky, most of the time more sources are needed to compare and confirm retrieved information. ${ }^{24}$ The results showed that the students apply stringent evaluation criteria such that their study quality was not affected by inaccurate information.

Contents provided in a scientific source that are supported by appropriate references are more credible. ${ }^{25}$ Considering citation principles and providing credible references in a scientific work show the author's sensitivity to choose and apply credible information in a correct way. It seems that some students evaluate credibility of information more precisely by considering references. In addition, a scientific source that has properly considered writing and grammatical principles and its contents are provided coherently is more likely to raise a sense of credibility and accuracy in users, thereby making it easier for users to trust it. ${ }^{26-27}$ Because the language of our country is not English, it is necessary to establish an office at the university for assessing and revising articles written by researchers and students in English. As the quality of writing improves, the produced information will draw more attention and be more frequently cited. The publication date of an information source plays an important role in the decision to use it. This criterion is being considered in different ways by users in various fields of science. In areas such as medical and associated health sciences, researchers seek information sources that have not been published a long time ago. ${ }^{28}$ The reason is rooted in the usefulness and non-repetitiveness of information provided in up-to-date scientific works. ${ }^{29}$ It seems that using more up-to-date information sources helps users obtain previous basic information with no need to study older scientific works in addition to having access to newer information in their desired field. In addition to the abovementioned reasons for using up-to-date information, students selecting topic and title for research work and dissertation search for new topics that can be first approved by the research council of the college and in the next step, increase the probability of publishing the resultant article.

No study was found in relation to the criterion of availability of facilities and equipment to replicate findings. The findings show that a lack of facilities and equipment in developing countries ${ }^{30-31}$ can be one of the reasons for researchers to consider the methods used in articles when deciding whether to use these articles. One of the reasons for students' consideration of the feasibility of conducting a study when evaluating an article is to comply with the policies of the university's vice-chancellor for research. Since almost all funding for studies at the university is provided by the office of the vice-chancellor for research and since one of the conditions for receiving funding is the publication of an article, students use replicability criteria to evaluate articles based on which they select a topic that it can be both carried out and published.

\section{Limitations}

Because of the lack of familiarity with the concepts of information evaluation despite the interviewer's explanation, after each interview question on how to evaluate and select an article or any other source of information, the participants were more likely to mention such problems as difficulty of accessing the information source and poor Internet connection and the interviewer had to spend more time exploring the evaluation of information credibility.

\section{CONCLUSION}

Students perform three levels of evaluation to obtain required information: database evaluation, information source evaluation and content evaluation. The criteria used to select a database are the availability of relevant and specialized information and the user-friendly features of the database. Librarians in School of Pharmacy should strive to conduct database training workshops to guide students on how to use all of the subscribed databases and allow them to use all available capacities. 
At the level of information source evaluation, students appreciated the ability to easily assess the author, publisher and journal to meet their information needs. At the level of content evaluation, students have used the replicability criterion for selecting repetitive studies for their research, in addition to evaluating the accuracy, relevancy and currency of information. According to this criterion, instead of evaluating the credibility of information, students consider whether they can use the materials and equipments to repeat the study such that they can choose an appropriate topic for their dissertation.

A future study will evaluate the reasons that researchers consider the replication criterion in evaluating papers and the advantages and disadvantages of this criterion.

\section{Ethics Statement}

This study was part of an MSc thesis supported and funded by TUOMS and approved by the Ethics Committee of TUOMS (under the code: IR.TBZMED. REC.1395.837).

\section{ACKNOWLEDGMENT}

The authors would like to thank the faculty members of School of Pharmacy for their help in completing the project and to thank the $\mathrm{PhD}$ students of this school who were involved in the project.

\section{CONFLICT OF INTEREST}

The authors declare no conflict of interest.

\section{ABBREVIATIONS}

WOS: Web of Science; TUOMS: Tabriz University of Medical Sciences; SJR: Scimago Journal Rank.

\section{REFERENCES}

1. Alaei S, Panahi S, Ghazavi SS, Zadeh JM. Strategy of health information seeking among physicians, medical residents and students after introducing digital library and information technology in teaching hospitals of Iran. Journal of Evidence-Based Medicine. 2015;8(2):91-7.

2. Ayatollahi A, Ayatollahi J, Ayatollahi F, Ayatollahi R, Shahcheraghi SH. Computer and Internet use among Undergraduate Medical Students in Iran. Pakistan Journal of Medical Sciences. 2014;30(5):1054.

3. Nemati AL, Babalhavaeji F. Investigating the awareness and ability of medical students in using electronic resources of the integrated digital library portal of Iran: A comparative study. The Electronic Library. 2013;31(1):70-83.

4. Asemi A. Information searching habits of Internet users: A case study on the Medical Sciences University of Isfahan, Iran. Webology. 2005;2(1):10.

5. Loo A, Chung CW. A model for information literacy course development: a liberal arts university perspective. Library Review. 2006;55(4):249-58.

6. Flanagin AJ, Metzger MJ. The role of site features, user attribute and information verification behaviors on the perceived credibility of web-based information. New Media and Society. 2007;9(2):319-42.
7. Tseng S, Fogg B. Credibility and computing technology. Communications of the ACM. 1999;42(5):39-44.

8. Hilligoss B, Rieh SY. Developing a unifying framework of credibility assessment: Construct, heuristics and interaction in context. Information Processing and Management. 2008;44(4):1467-84.

9. Kupferberg N, Protus BM. Accuracy and completeness of drug information in Wikipedia: an assessment. Journal of the Medical Library Association : JMLA. 2011;99(4):310-3. PubMed PMID: PMC3193353.

10. Inclusion Guidelines for Webmasters [cited 201724 November]. Available from: https://scholar.google.com/intl/en/scholar/inclusion.html.

11. Lincoln YS, Guba EG. Judging the quality of case study reports. The Qualitative Researcher's Companion. 2002:205-15.

12. Creswell JW. Research design: Qualitative, quantitative and mixed methods approaches: SAGE Publications, Incorporated. 2009.

13. Adeoye MO, Popoola S. Teaching effectiveness, availability, accessibility and use of library and information resources among teaching staff of schools of nursing in Osun and Oyo State, Nigeria. Library Philosophy and Practice. 2011.

14. Chen C, Yu Y, Tang Q, Chiu K, Rao Y, Huang X, et al. Assessing the authority of free online scholarly information. Scientometrics. 2012;90(2):543-60.

15. Metzger MJ, Flanagin AJ. Credibility and trust of information in online environments: The use of cognitive heuristics. Journal of Pragmatics. 2013 2013/12/01/;59:210-20.

16. Harzing AW. A longitudinal study of Google Scholar coverage between 2012 and 2013. Scientometrics. 2014;98(1):565-75.

17. $\mathrm{Xu} \mathrm{H}$. Factors affecting faculty use of learning object repositories. The Electronic Library. 2015;33(6):1065-78

18. Cader R. Judging Nursing Information on the World Wide Web. CIN: Computers, Informatics. Nursing. 2013;31(2):66-73. PubMed PMID: 00024665-201302000-00004.

19. Ahmad R, Komlodi A, Wang J, Hercegfi K. The impact of user experience levels on web credibility judgments. Proceedings of the American Society for Information Science and Technology. 2010;47(1):1-4

20. List A, Grossnickle EM, Alexander PA. Undergraduate Students' Justifications for Source Selection in a Digital Academic Context. Journal of Educational Computing Research. 2015

21. Winter S, Kramer NC, Appel J, Schielke K. Information Selection in the Blogosphere: The Effect of Expertise, Community Rating and Age. Proceedings of the Cognitive Science Society. 2010;32(32).

22. Hasan L, Abuelrub E. Assessing the quality of web sites. Applied Computing and Informatics. 2011;9(1):11-29.

23. Walraven A, Brand-Gruwel S, Boshuizen HP. Fostering students' evaluation behaviour while searching the internet. Instructional Science. 2013;41(1):125-46.

24. Rieh SY, Hilligoss B. College students' credibility judgments in the informationseeking process. Digital Media, Youth and Credibility. 2008:49-72.

25. Rains SA, Karmikel CD. Health information-seeking and perceptions of website credibility: Examining Web-use orientation, message characteristics and structural features of websites. Computers in Human Behavior. 2009;25(2):544-53.

26. Lucassen T, Schraagen JM. Factual accuracy and trust in information: The role of expertise. Journal of the American Society for Information Science and Technology. 2011;62(7):1232-42.

27. Pickard AJ, Shenton AK, Johnson A. Young people and the evaluation of information on the World Wide Web: Principles, practice and beliefs. Journal of Librarianship and Information Science. 2012.

28. Salinas GD. Trends in physician preferences for and use of sources of medical information in response to questions arising at the point of care: 2009-2013. Journal of Continuing Education in the Health Professions. 2014;34(S1).

29. Mohammadi F, Abrizah A, Nazari M. Is the information fit for use? Exploring teachers perceived information quality indicators for Farsi web-based learning resources. Malaysian Journal of Library and Information Science. 2015;20(1):99-122.

30. Öman $\mathrm{CB}$, Gamaniel KS, Addy ME. Properly functioning scientific equipment in developing countries. ACS Publications. 2006.

31. Vose P, Cervellini A. Problems of scientific research in developing countries. IAEA Bulletin. 1983;25(2):37-40. 


\section{PICTORIAL ABSTRACT}

Pharmacy Students' Information Credibility Evaluation Study

Method: Qualitative study using semi-structured interviews

Samples: 13 pharmacy $\mathrm{PhD}$ students

Data analysis: Content analysis approach

Extracted criteria: categorised in three themes:

a) database evaluation criteria

- Accessibility

- Coverage

- Leamability

b) information sources evaluation criteria

- Authority

- Source validity

c) content evaluation criteria

- Accuracy

- Relevancy

- Replicability

- Currency

\section{SUMMARY}

- This study was designed to fill the gap in the literature regarding the scientific and research-based understanding of the criteria used by students to evaluate the credibility of information used for research purposes. The analysis of the data obtained from the interviews showed that students perform three levels of evaluation to obtain required information: database evaluation, information source evaluation and content evaluation. At the level of content evaluation, students have used the replicability criterion for selecting repetitive studies for their research, in addition to evaluating the accuracy, relevancy and currency of information.

\section{About Authors}

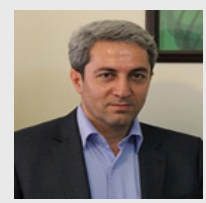

Shafi Habibi, PhD received his PhD degree in Health Information Management in 2015 from Iran University of Medical Sciences, Tehran, Iran. His research interests include information seeking behavior, information retrieval and datamining. He is working in department of librarianship and medical information science, School of Management and Medical Informatics, Tabriz University of Medical Sciences, Tabriz, Iran.

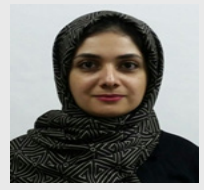

Seyede Nasrin Fatemi, MSc has been graduated in librarianship and medical information science from Tabriz University of Medical Sciences, School of Management and Medical Informatics in 2018.

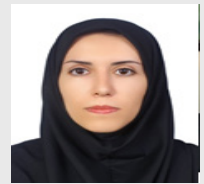

Doshmangir, Ph.D Assistant professor of health policy in Tabriz University of Medical Sciences. Her main interests are evidence informed health policy, health systems reform, health policy analysis and financing. She is expert in applying different qualitative, review research and mixed study methodologies for answering health policy and health system questions.

Cite this article: Habibi S, Fatemi SN, Doshmangir L. How Pharmacy Students Evaluate the Credibility of Scientific Information: A Qualitative Study. Indian J of Pharmaceutical Education and Research. 2019;53(1):79-87. 